HEAVY SECTION STEEL TECHNOLOGY PROGRAM

\section{5 th}

ANNUAL INFORMATION MEETING

MARCH 25-26, 1971

Paper No. 25

PREFIMINARY RESUITS OF SIPEEY MODEL TESTSS

R. W. Derby

Dak Ridge National Laboratory

Oak Riage, Tennessee

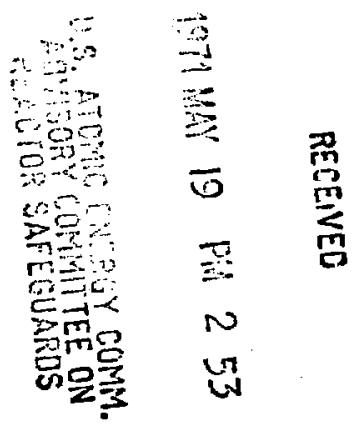

MASTER

Sponsoring Program or Organization

HEAVY SECTION STEERL TECHNOLOGY PROGRAM

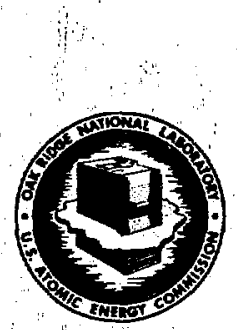

OAK RIDGE NATIONAL LABORATORY

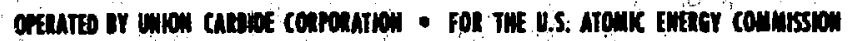


PRELIMINARY RESULTS OF STEEL MODEL TESTS

R. W. Derby

Oak Ridge National Laboratory

\section{Introduction}

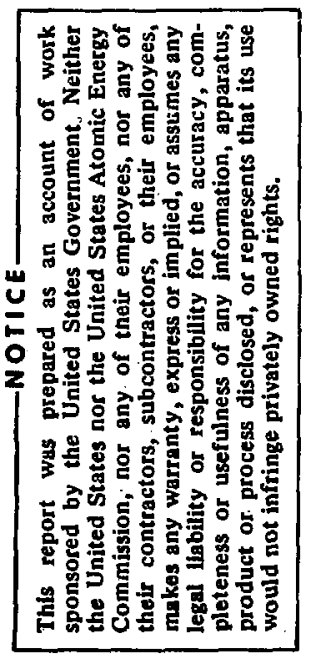

There were five purposes for the tests described below:

1. To find a transition temperature for a flawed structure in a multiaxial state of stress.

2. To provide quantitative information for other more theoretically oriented investigations such as those of Randall, Witt, Lubahn, Merkle.

3. To examine in a quslitative way the influence of pneumatic loading on the mode of failure of a pressure vessel.

4. To demonstrate in a small, but quantitative, way that the margin of safety implicit in the ASME pressure vessel code is not seriously reduced by the presence of sharp flaws.

5. To help anticipate problems which may arise in testing a series of geometrically similar, but much larger vessels.

\section{Fabrication and Material}

The models were turned from blocks cut out of HSST plate 01. See Fig. 1 for location in plate. The long axis of the model was made to coincide with the thickness direction of the plate. This orientation puts any laminations which were in the plate perpendicular to the axial direction rather than the hoop direction where they would be more serious.

An artificial flaw was put into the vessels using the technique developed by Canonico and described elsewhere in the program. Note that the flaw is perpendicular to the rolling direction as would be a flaw in a vessel under the most unfavorable conditions. See Fig. 2.

The actual dimensions of the smaller of two sizes are shown in Fig. 3 . (The other vessels were twice as large.)

It should be emphasized that the vessels are relatively thick-walled. This point is emphasized by application of Lame's equation to the vessels. See Fig. 4 . 


\section{Test Results}

1. The gross strain in the smaller models as observed at a number of temperatures and pressures is shown in Table 1. (Gross strain is defined as the strain in the hoop direction at a point remote from the flaw.) The most important point is the excellent reproducibility.

It should be added that the EA-06 are general purpose gages for use on material with expansion coefficient of $6 \times 10^{-6} \mathrm{in} . / \mathrm{in} . /^{\circ} \mathrm{F}$, whereas the EP-08 are high elongation gages in which temperature compensation is not considered important.

2. The load-strain curves for both sizes of vessel are shown in Fig. 5. The results are summarized in Tables 2 and 3. As can be seen by inspection of both the graph and tables, a clearly defined transition in behavior takes place over a relatively narrow temperature region. Unfortunately any scale effect is masked by the apparent variation in material property.

The residual radial growth as a function of distance from the midplane of the vessel is shown in Fig. 6 fore one temperature below and one above the transition. (Barrel effect.)

3. Some experts had expressed the opinion that the large amount of stored energy in a pneumatically loaded vessel might automatically lead to a failure with fragmentation regardless of temperature. None of whe pneumatically tested vessels developed fragments although much larger openings occurred than with hydraulic loading. The pneumatically induced failures, however; can in no way be called leaks.

4. If the vessels described in this paper were to be operated by ASME code rules then the maximum permissible pressure would be 9400 psi. Clearly, even the combination of flaw and low temperature does not greatly decrease the margin of safety. For an unflawed vessel the ratio of burst to code pressure was slightly better than four whereas for the flawed vessels it was, with one exception, siightly better than three.)

5. A number of interésting observations were made during the experiments. 
(a) (Low temperature creep was observed as low as $26^{\circ} \mathrm{F}$.) At room temperature the creep was observed with both dial and foil gages. (Even for relatively small increments of pressure, as much as five minutes would often be required for the vessel to stop growing. This effect emphasizes the need for planning a loading rate.)

(b) Our low temperature hydraulic fluid, triethyl phosphate, worked well except when contaminated by droplets of oil which would solidify under the influence of high pressure and low temperature, thus completely blocking the high pressure tubing between the pump and the vessel. Although this was an interesting curiosity for our small-scale tests, the cleaning required on a largescale test would be annoying and time-consuming.

(c) The use of bonded strain gages to measure large strains at low temperatures has not been completely successful. Hence backup methods are recomended. First, pairs of dial gages mounted on a diameter can be used to infer hoop strain by using the compatibility relation. Second, a tool maker's microscope can be used for before and after measurements with an accuracy of 0.0001 in. in a gage length of 0.5000 in. 


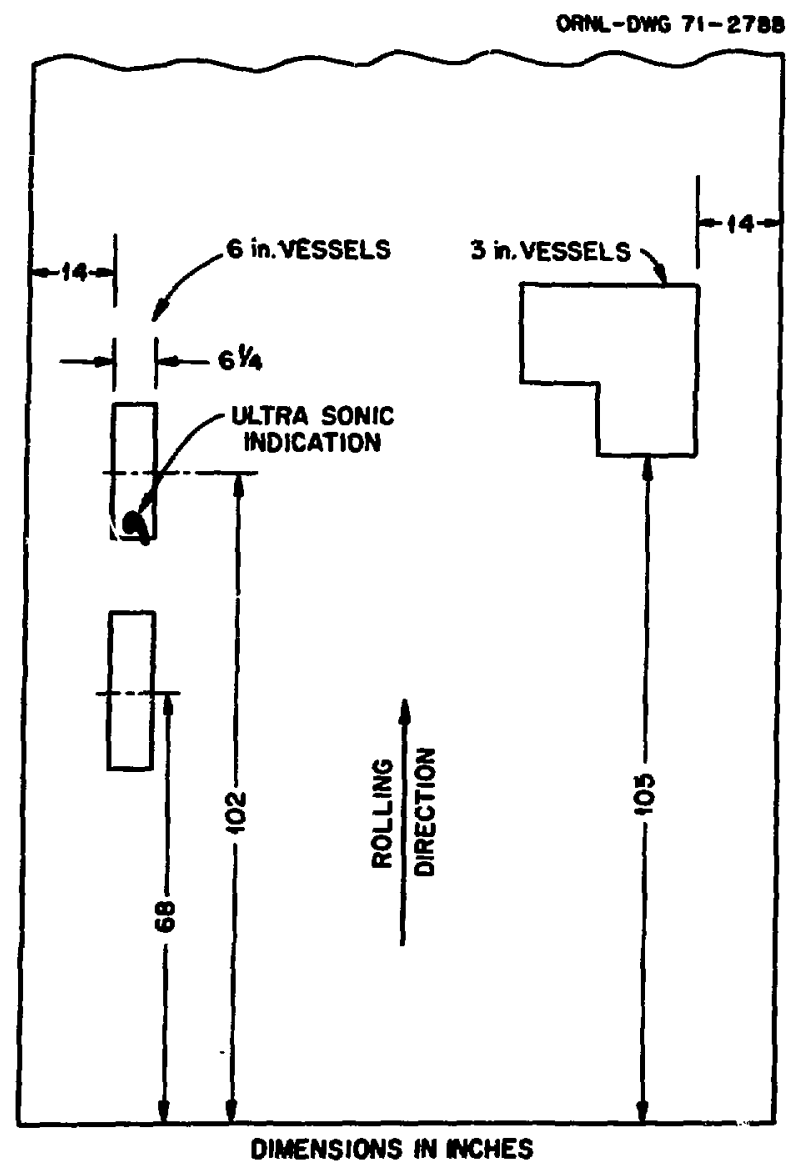

Fig. 1. Material Location in Plate OI. 


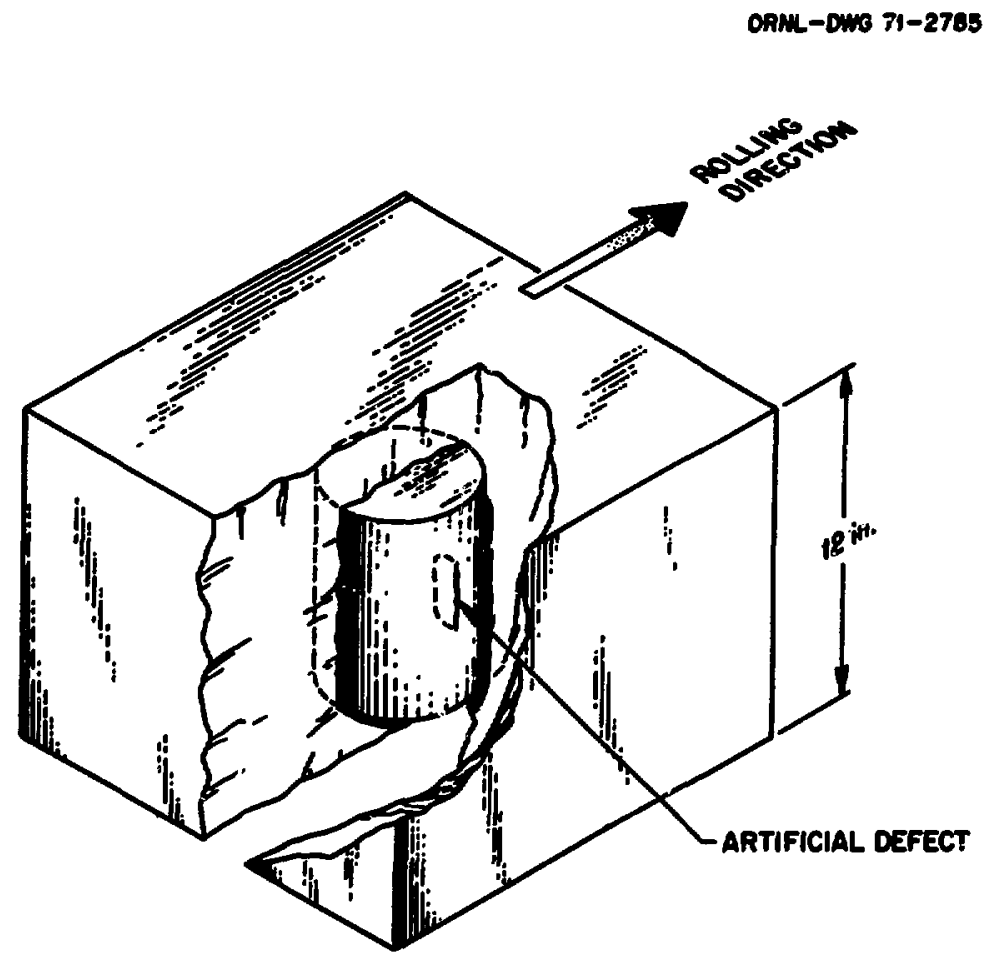

Fig. 2. Orientation of Vessels wilh Respect to Plate. 


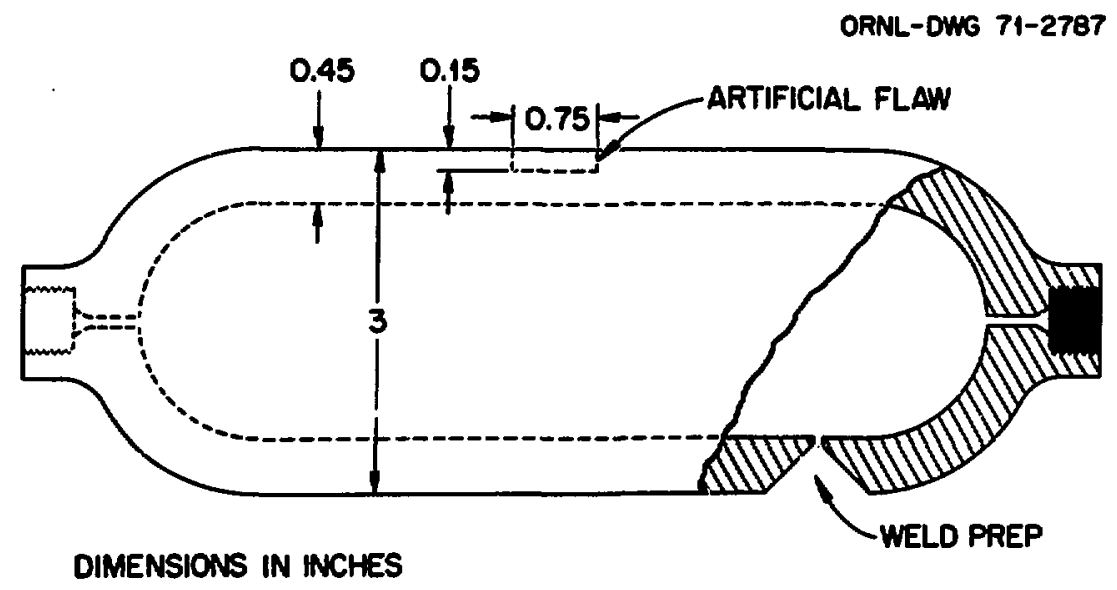

Fig. 3. Sketch of 3-in.-diam Vessels. 


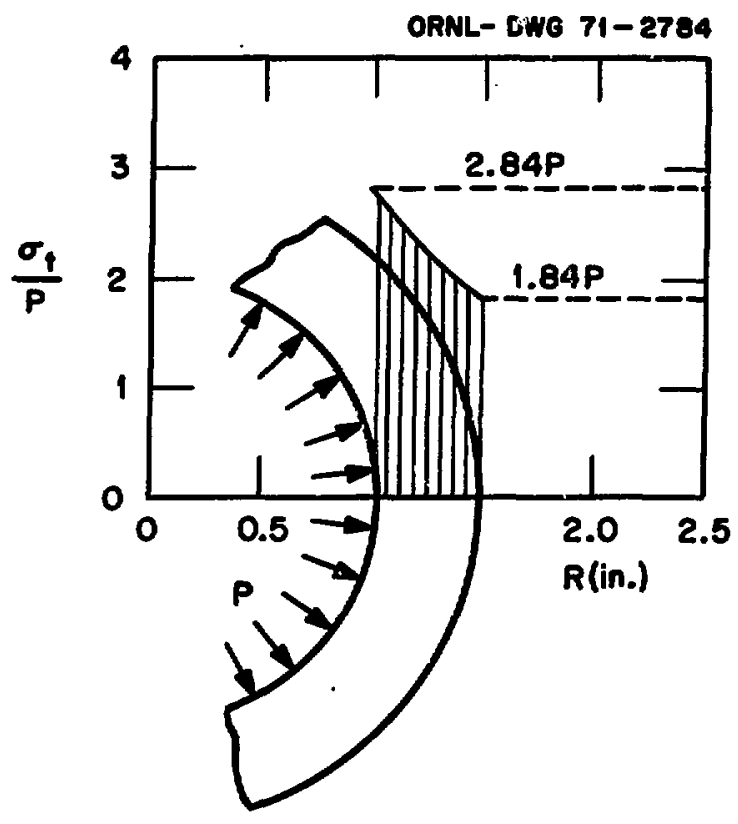

Fig. 4. Hoop Stress Distribution in 3-in. Vessels. 


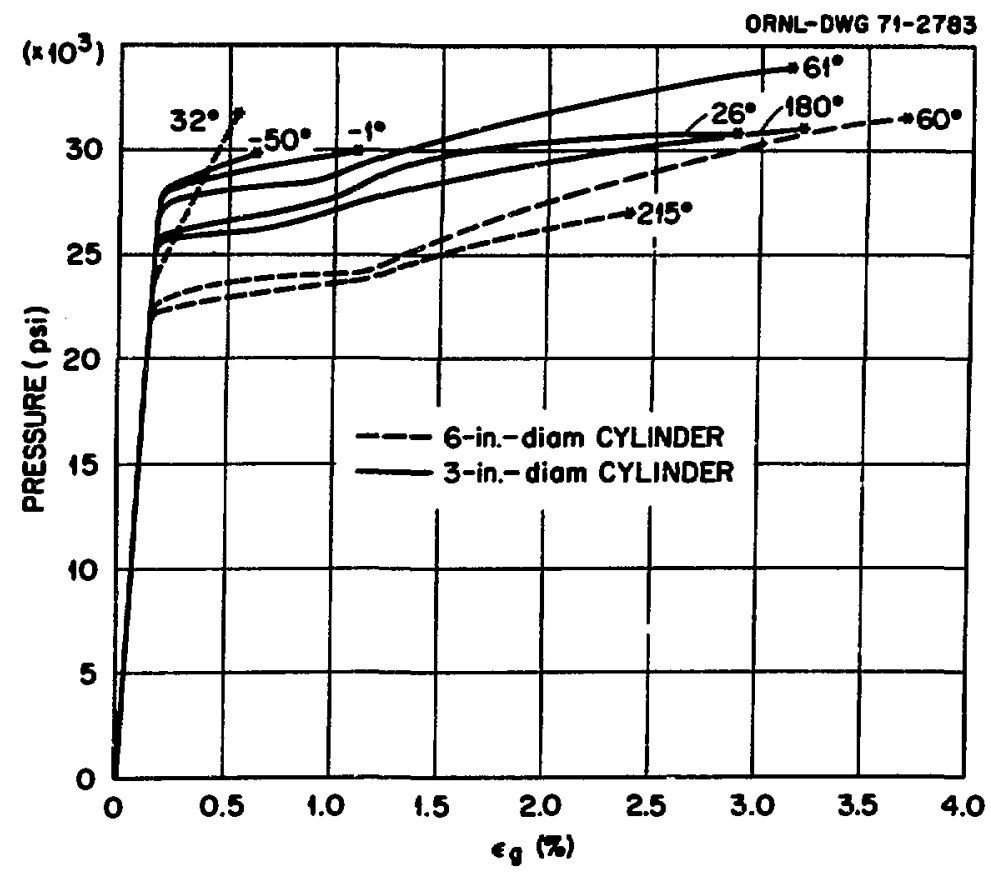

Fig. 5. Pressure-Steam Curves. 


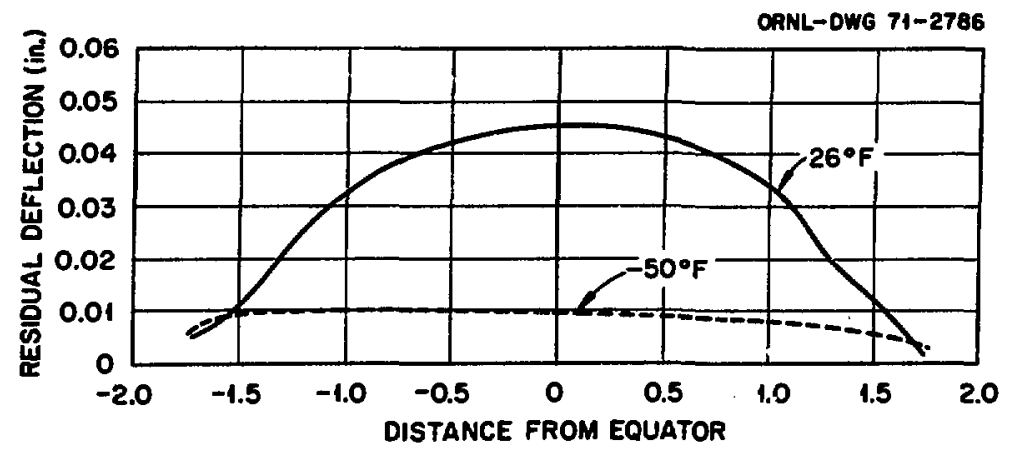

Fig. 6. Barreling of Two Vessels After Test. 
Table 1. Hoop Strain in Microinches/in. on Gross Section at Different Temperatures and Pressures

\begin{tabular}{|c|c|c|c|c|c|c|c|c|}
\hline \multirow{2}{*}{$\begin{array}{l}\text { Temp. } \\
\left({ }^{\circ} \mathrm{F}\right)\end{array}$} & \multicolumn{7}{|c|}{ Pressure, psi } & \multirow{2}{*}{$\begin{array}{l}\text { Type } \\
\text { Gage }\end{array}$} \\
\hline & 4000 & 8000 & 12,000 & 16,000 & 20,000 & 22,000 & 24,000 & \\
\hline-46 & 190 & 430 & 645 & 845 & 1055 & 1135 & 1260 & $\mathrm{EA}-06$ \\
\hline-1 & 210 & 430 & 640 & 820 & 1060 & 1165 & 1370 & $\mathrm{EP}-08$ \\
\hline 20 & 205 & 445 & 695 & 900 & 1105 & 1285 & 1590 & EP-08 \\
\hline 32 & 192 & 403 & 622 & 832 & 1070 & 1192 & 1385 & EA-06 \\
\hline 61 & 200 & -- & 640 & 820 & 1050 & 1170 & 1365 & EP-08 \\
\hline 70 & -- & -- & 675 & -- & 1120 & 1265 & 1480 & EA-06 \\
\hline 190 & 210 & 425 & 640 & 855 & 1092 & 1280 & 1565 & EA-06 \\
\hline
\end{tabular}


Table 2. Summary 3-in. Vessel Tests

\begin{tabular}{cccc}
\hline $\begin{array}{c}\text { Temp. } \\
\left({ }^{\circ} \mathrm{F}\right)\end{array}$ & $\begin{array}{c}\text { Failure Pressure } \\
\left(\mathrm{psi} \times 10^{3}\right)\end{array}$ & $\begin{array}{c}\text { Remote Strain } \\
\left(\epsilon_{\mathrm{g}}, \%\right)\end{array}$ & $\begin{array}{c}\text { Loading and } \\
\text { Failure Mode }\end{array}$ \\
\hline-50 & 30 & 0.64 & Hydraulic, break \\
-1 & 30 & 1.1 & Hydraulic, break \\
26 & 31 & 2.9 & Hydraulic, leak \\
61 & 34 & 3.2 & Hydraulic, leak \\
$\approx 130$ & 34 & $-2-$ & Pneumatic, burst \\
180 & 32 & 3.2 & Pneumatic, burst \\
60 & 38 & $>10$ & Unflawed, hydraulic \\
\hline
\end{tabular}

Table 3. Summary 6-in. Vessel Tests

\begin{tabular}{lccc}
\hline $\begin{array}{l}\text { Temp. } \\
\left({ }^{\circ} \mathrm{F}\right)\end{array}$ & $\begin{array}{c}\text { Failure Pressure } \\
\left(\mathrm{psi} \times 10^{3}\right)\end{array}$ & $\begin{array}{c}\text { Remote Strain } \\
\left(\epsilon_{\mathrm{g}}, \mathrm{g}\right)\end{array}$ & $\begin{array}{l}\text { Loading and } \\
\text { Failure Mode }\end{array}$ \\
\hline 32 & 31.5 & 0.45 & Hydraulic, break \\
60 & 31.5 & 3.7 & Hydraulic, leak \\
215 & 27.6 & 2.4 & Pneumatic, burst \\
\hline
\end{tabular}

